\title{
Post Massive Weight Loss Lower Bodylift a Comparative Study between Belt Lipectomy and Lockwood Technique
}

\author{
HAZEM H. DAHSHAN, M.Sc.; AYMAN FARAHAT, M.D.; MOHAMOUD NASEF, M.D.; \\ AHMED M. EL-MOFTY, M.D. and ABDO EL-BANA, M.D.
}

The Department of Plastic \& Burn Surgery, Faculty of Medicine, Al-Azhar University

\begin{abstract}
Purpose: Measurements of improvement or elimination of post massive weight loss skin panniculus by Lockwood lower body lift\#2 technique and Belt lipectomy and compare the result of both in lower body lift.

Methods: These prospective study includes 30 patients having lost weight greater than 25 percent of their body weight and have stabilized their weight loss not less than 6 month through bariatric surgery or with diet.

Results: The result of this prospective study demonstrate the hazards of lockwood lower body lift\#2 is more than in belt lipectomy procedure.

Conclusions: The benefits of lockwood lower body lift\#2 is not obvious comparing to the hazard of this maneuver, as the patient always need complementary thigh lift in another session especially in post massive weight patient.
\end{abstract}

Key Words: Lockwood lower body lift\#2 - Belt lipectomy Post massive weight loss lower bodylift.

\section{INTRODUCTION}

Around the year 2000, bariatric surgery experienced a boom which has led to a new group of patients, collectively referred to as "massive weight loss patients". Because of the circumferential nature of this group's deformities, lower body lift is fast becoming a main stream operation in plastic surgery [1].

Massive weight loss helps to relieve patients of many of their medical problems but often does not eliminate the psychological issues. Therefore, body lift/belt lipectomy procedures are very helpful in reducing the rate of psychological problems [2].

Lower body lift proceducers improve abdominal contour, abdominal wall laxity, mons pubis ptosis, back roll, waist contour, and buttock contour [3].
The term belt lipectomy, first coined by Gonzalez-Ulloa in 1960, his technique include vertical wedge resection of the mons pubis anteriorly and the midline, posteriorly to reduce the circumferential excess [4].

In 1993, lockwood presented the original lowerbody lift design, referred as lower-body lift \#1, which combines the anchor medial-thigh lift (1988) and the transverse-flank/thigh/buttock lift (1991) [5].

In 1996, lockwood combined the high-lateraltension abdominoplasty with the transversethigh/buttock lift for generalized trunk and thigh relaxation, a technique referred to hereafter as the lower-body lift \#2 (our study discuss these technique and compare it with belt lipectome) [6].

\section{PATIENTS AND METHODS}

These prospective study includes 30 patients (from January 2015 till January 2018) having lost weight greater than 25 percent of its body weight and have stabilized their weight loss not less than 6 month through bariatric surgery or with diet.

Measurements of improvement or elimination of post massive weight loss skin panniculus by Lockwood lower body lift\#2 technique (15 patients) and Belt lipectomy (15 patients) and compare the result of both in lower body lift.

Our study focus on Operative time, Hospital stay (ICU stay), Rehabilitation time, Need to Blood transfusion, Rate of complications (Objective evaluation) and also patient satisfaction as regard Physical activity, Psychological impact, Self-image, Sexual performance, Social activity (subjective evaluation). 
Lockwood technique is different on belt lipectomy in the overall circumferential wedge of resection is located lower onto the lower trunk. The procedure can be thought of as a truncal-thigh lift, not just a truncal lift. The bilateral zones of adherence located between the hip and trochanteric fat deposits are intentionally destroyed to allow the surgeon to lift the lateral and anterior thighs very aggressively.

Table (1): The differences between belt lipectomy and lower body lift\#2 (as regard technical point) are summarized in the following table.

\begin{tabular}{lll}
\hline & \multicolumn{1}{c}{$\begin{array}{c}\text { Lower } \\
\text { body lift\#2 } \\
\text { lipectomy }\end{array}$} \\
\hline Circumferential wedge & Both lower trunk and thighs are treated as a unit & Lower trunk is treated as a unit \\
Zones of adherence & More inferiorly positioned & More superiorly positioned \\
Thigh lift & Completely eliminated & Weakened but maintained \\
Accentuation of waist & May blunt & Elevation is moderate \\
\hline
\end{tabular}
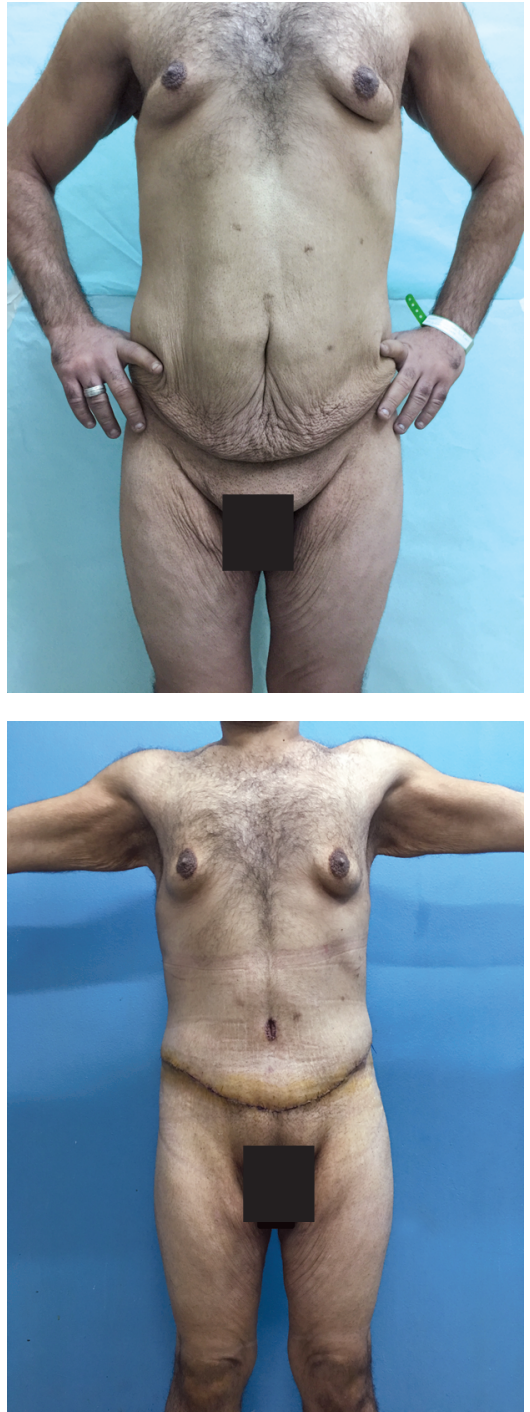
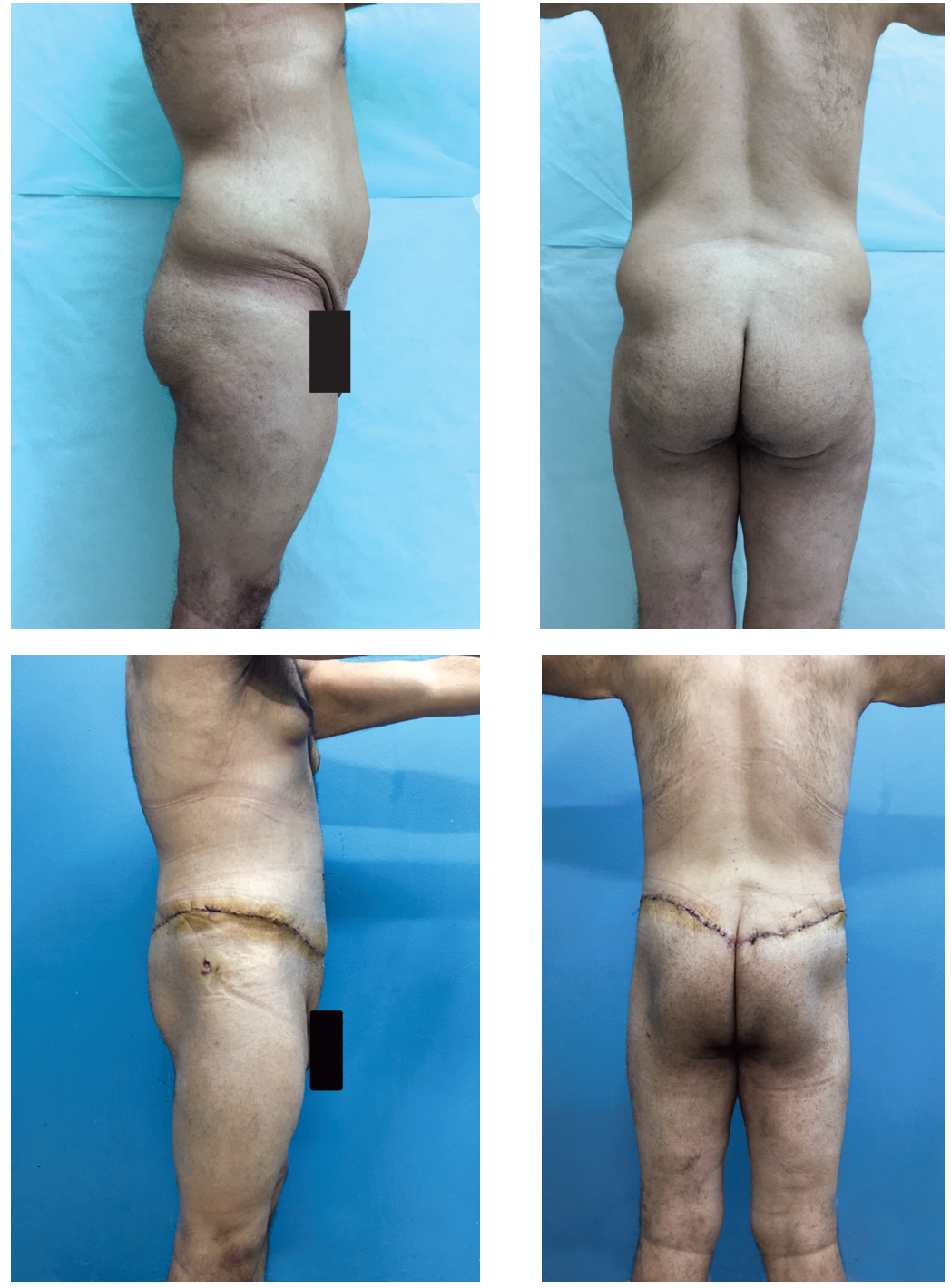

Fig. (1): Belt lipectomy: Preoperative and post operative (anterior, lateral and posterior view). 

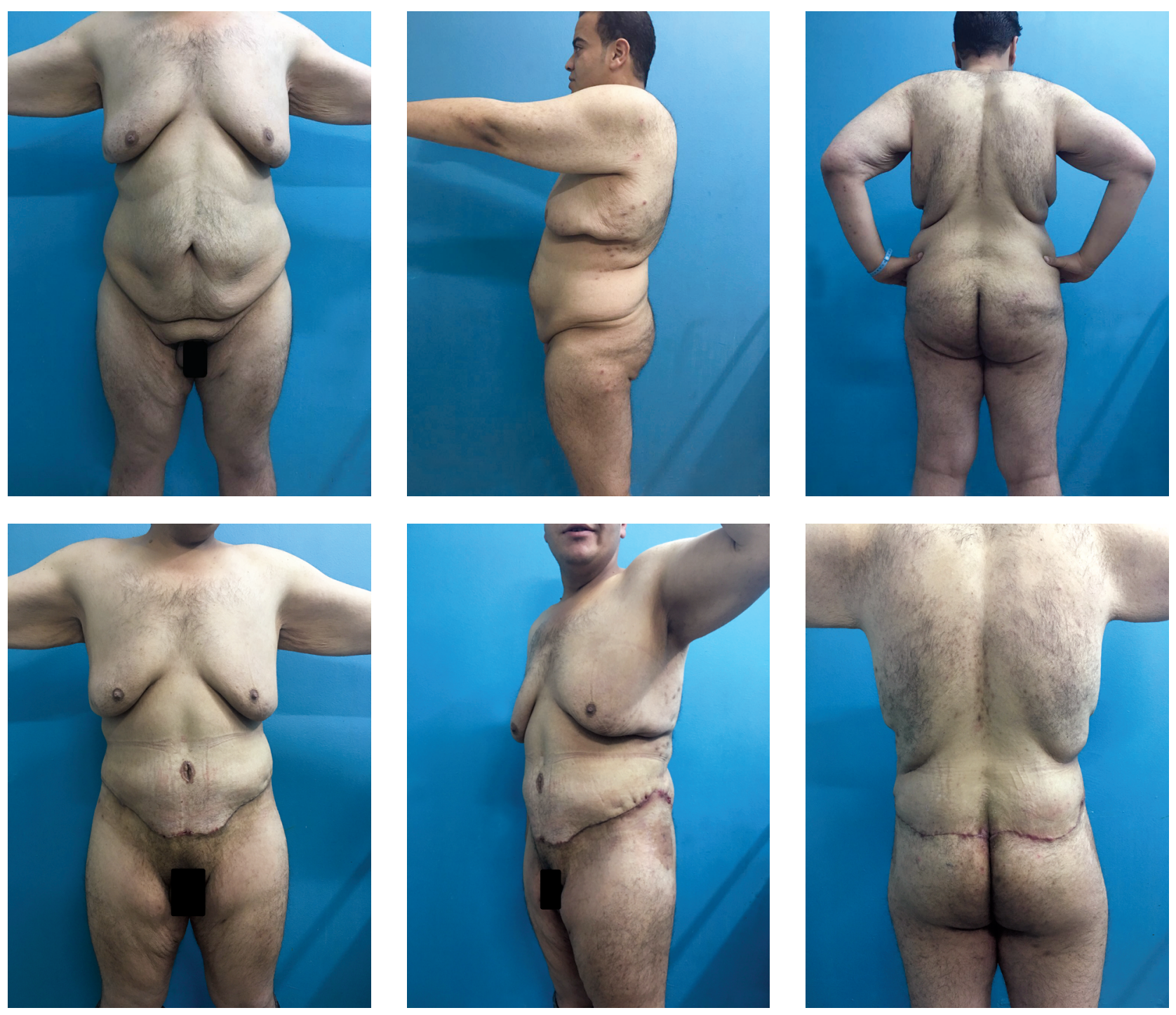

Fig. (2): Lockwood technique: Preoperative and post operative (anterior, lateral and posterior view).

\section{RESULTS}

In belt lipectomy: The study comprised from ten female and five male with age range between 21 and 45 years old (mean 27.9), Body mass index (BMI) at time of operation range between 27 and 31.5 (mean 29.45), heamoglobin range between 10 and 14 (mean 12.2), thirteen patients lose its weight by bariatric surgery two patients by diet.

In lockwood: The study comprised from seven female and seven male with age range between 21 and 35 years old (mean 27.3), Body mass index (BMI) at time of operation range between 25 and 31 (mean 27.8), heamoglobin range between 11 and 14 (mean 12.5), fourteen patients lose its weight by bariatric surgery one patient by diet.
Table (2): The result of this prospective study demonstrate the hazerd of lockwood lower body lift\#2 is more than in belt lipectomy procedure as shown in table below.

\begin{tabular}{lll}
\hline & $\begin{array}{c}\text { Lockwood } \\
\text { lower body lift\#2 }\end{array}$ & $\begin{array}{c}\text { Belt } \\
\text { lipectomy }\end{array}$ \\
\hline Time of operation / hours & $\begin{array}{l}\text { Avarege 7 hours } \\
\text { Avarege 8 days }\end{array}$ & $\begin{array}{l}\text { Avarege 5 hours } \\
\text { Avarege 5 days }\end{array}$ \\
Hospital stay / days. & $\begin{array}{l}\text { 7 patient (50\%) } \\
\text { 2 patient (13\%) }\end{array}$ \\
$\begin{array}{lll}\text { Postoperative ICU/ No of } \\
\text { patient needed }\end{array}$ & & Avarege 1.8 \\
Blood trasfusion (whatever & Avarege 2.6 & \\
whole blood or packed red & & \\
blood cells) during opera- & & \\
tion or postoperative /liters & & \\
Rat e of complication: & & $13 \%$ \\
Seroma & $33 \%$ & $7 \%$ \\
Hematoma & $20 \%$ & $7 \%$ \\
Wound infection & $33 \%$ & $0 \%$ \\
$\quad$ Wound dehiscence & $13 \%$ & $0 \%$ \\
$\quad$ Skin necrosis & $7 \%$ & $7 \%$ \\
Scar migration & $13 \%$ & $7 \%$ \\
Lymphydema & $27 \%$ & \\
\hline
\end{tabular}


In spite of that objective data which collected , the patient satisfactions as regred Physical activity, Psychological impact, Self image, Sexual performance, Social activity which undergo to lockwood lower body lift\#2 is not more than patients perform belt lipectomy but maybe less as shown in table below.

Table (3):Subjective evaluation (patient questioner).

\begin{tabular}{lll}
\hline & Belt lipectomy & Lockwood \\
\hline 1- Physical activity: & & \\
Good & $20 \%$ & $27 \%$ \\
Very good & $80 \%$ & $60 \%$ \\
Excellent & $0 \%$ & $13 \%$ \\
2- Psychological impact: & & \\
Fair & $0 \%$ & $13 \%$ \\
Good & $20 \%$ & $33 \%$ \\
Very good & $40 \%$ & $27 \%$ \\
Excellent & $40 \%$ & $27 \%$ \\
3- Self-image: & & \\
Fair & $7 \%$ & $7 \%$ \\
Good & $13 \%$ & $40 \%$ \\
Very good & $40 \%$ & $27 \%$ \\
Excellent & $40 \%$ & $26 \%$ \\
4- Sexual performance: & & \\
Fair & $9 \%$ & $0 \%$ \\
Good & $9 \%$ & $30 \%$ \\
Very good & $27 \%$ & $50 \%$ \\
Excellent & $55 \%$ & $20 \%$ \\
5- Social activity & & \\
Fair & $0 \%$ & $7 \%$ \\
Good & $20 \%$ & $40 \%$ \\
Very good & $53 \%$ & $20 \%$ \\
Excellent & $27 \%$ & \\
\hline
\end{tabular}

\section{DISCUSSION}

From the previous data, the benefits of lockwood lower body lift\#2 is not obvious comparing to the hazard of this maneuver, as the patient always need complementary thigh lift in another session especially in post massive weight patient.

We would like to emphasize that operation (lockwood lower body lift\#2) of this magnitude have a significant potential for serious, sometimes life-threatening, complications. As always, careful patient selection and efficient, minimally traumatic surgery will reduce the likelihood of all complications.

\section{Conclusion:}

For the surgeon who is new to body lifting, it is prudent to perform each component of the "combined" lift separately to gain experience with simple procedures before attempting a complex one. Thigh lift, belt lipectomy can each be performed separately for staged torso and thigh reconstruction.

\section{REFERENCES}

1- Al S. Aly: Surgical Technique by Anatomic Region. In: Body Contouring After Massive Weight Loss. (II): 59237, 2006.

2- Sarwer D.B. and Fabricatore A.N.: Psychiatric considerations of the massive weight loss patient. Clin. Plast. Surg., 35 (1): 1-10, 2008.

3- Al S. Aly, Cram A.E. and Heddens C.: Truncal body contouring surgery in the massive weight loss patient. Clin. Plast. Surg., Oct., 31 (4): 611-24, 2004.

4- González-Ulloa.: British journal of plastic surgery13 179, 1960.

5- Lockwood T.: Lower body lift with superficial fascial system suspension, Plast. Reconstr. Surg., 92: 1112-1122, 1993.

6- Lockwood T. Lower body lift. Oper. Tech. Plast. Reconstr. Surg., 3: 132-144, 1996. 